\title{
Essential oil yield and stability of various Rosa damascena Mill Landraces under different ecological conditions
}

\begin{abstract}
Essential oil (EO) production is the main objective of Damask rose cultivation but its stability at different environments has not been well documented. In order to this, 35 landraces of Damask rose were studied at 7 locations in Iran during 20078. The analysis of variance revealed significant differences $(\mathrm{p} \leq 0.01)$ in $\mathrm{EO}$ among landraces (G), locations (L), Years (Y/L) and for landrace $\times$ location (GL) interaction. A large portion of EO variation was attributed to environment (Location-year) and landrace $\times$ environment (GE) effects. The GL interaction was mainly crossover and mainly accounted for by non-linear (unpredictable) component. The total mean of EO was $286 \mathrm{ppm}$ and Kashan with $681 \mathrm{ppm}$ and the landraces of SM2, SM1, AK1 and BA1 with $547,442,440$ and $427 \mathrm{ppm}$ respectively produced the highest oil among studied locations and landraces. According to the results, most of landraces that originated from warm temperate and arid regions produced higher EO than those from cool, semi-arid and humid regions. There was high consistency of stable genotypes with two stability models of Eberhart \& Russell ${ }^{1}$ and Shukla's ${ }^{2}$ stability variance $\left(\sigma i^{2}\right)$ and according to them the landraces of CM1, QM1, KZ1, KS1 and HO1 were general stable with dynamic stability concept. In addition, we recommend the landrace of CM1 as moderate essential oil with general stability and adaptability in different environments and locations, furthermore, SM1 and BA1 can be recommended as superior essential oil with specific adaptability for warm and arid of the southern part (Khuzestan, etc.) and SM2 and AK1 for temperate and cool areas of the northern half (Isfahan, Khorasan etc.) in Iran.
\end{abstract}

Keywords: adaptability, aromatic - medicinal plants, damask rose (rosa damascena mill.), dynamic stability
Volume 2 Issue 5 - 2018

\begin{abstract}
Bayzid Yousefi,' Sayed Reza Tabaei Aghdaei ${ }^{2}$ 'Kurdistan Agricultural and Natural Resources Research and Education Center, AREEO, Sanandaj, Islamic Republic of Iran ${ }^{2}$ Research Institute of Forests and Rangelands, Agricultural Research, Education and Extension Organization (AREEO), Tehran, Islamic Republic of Iran
\end{abstract}

Correspondence: Bayzid Yousefi, Kurdistan Agricultural and Natural Resources Research and Education Center,AREEO, P. O. Box: 66169-363II, Sanandaj, Islamic Republic of Iran, Email bayzidyousefi@gmail.com

Received: December 9, 2018 | Published: October 24, 2018

\section{Introduction}

Essential oil production is the main objective of Damask rose (Rosa damascena Mill.) cultivation in many areas of the world e.g. Bulgaria, Turkey, India etc., ${ }^{3}$ thus, essential oil is the most important trait in this crop. Besides its application in aromatic industries, some valuable characteristics of rose oil such as anti-HIV, antibacterial and antioxidant activities have been demonstrated recently. ${ }^{4,5}$ Essential oil is a complex trait, which is depended on yield components and is influenced by many genetic as well as environmental factors. Therefore evaluating of genotypes potential in different environments (location and years) is the important step in breeding programs of Damask rose before selecting desirable ones to commercial cultivation. A desirable landrace is one that does not only essential oil well in its area of initial selection but also maintains the high yielding ability over a wide range of environments. To identify such genotypes stability analysis is a good technique that measures the adaptability of different crop varieties to varying environments. ${ }^{6}$ Since, the literature on the effects of genotype - environment compatibility and stability are low in Rosa damascena, inevitably, should refer to the methods used in similar plants. Eberhart \& Russell ${ }^{1}$ model has widely used for evaluating of yield stability in both annual and perennial plants same as Campanula rapunculoides, ${ }^{7}$ Hevea brasiliensis ${ }^{8,9}$ and Thea $s p^{10}$ Eberhart \& Russell ${ }^{1}$ considered a stable genotype to have a slope ( $b$ value) equal to unity and deviation from regression $\left(S^{2}{ }_{d}\right)$ equal to zero. Freeman ${ }^{11}$ and Bernardo ${ }^{12}$ described the Eberhart \& Russell ${ }^{1}$ model as the most widely used methods for evaluating of yield stability among main classical parametric methods that determine general and specific dynamic stability (adaptability) and measures linear and nonlinear components of stability. Furthermore, multivariate methods of stability such as AMMI, while statistically more complex, despite of widely uses in annual plants, has no advantages over the conventional methods in perennial crops and forest trees and its application is limited. ${ }^{13,14}$ We were also interested to know the contribution of each genotype in genotype $\times$ environmen (GE) interaction sum of squares. To do this, there are two stability parameters of Wricke's ${ }^{15}$ ecovalence $\left(\mathrm{W}_{\mathrm{i}}\right)$ and Shukla's ${ }^{2}$ stability variance $\left(\sigma_{i}^{2}\right)$ which give the same results for ranking genotypes. ${ }^{16}$ Shukla ${ }^{2}$ the stablility variance of genotype as its variance across invironments after the main effects of environmental means have been removed. He used stability variance $\left(\sigma_{i}^{2}\right)$ to estimate a component of the GE interaction corresponding to each genotype. According to his model, genotypes with a low $\sigma_{i}^{2}$ have smaller deviations from the mean across environments and thus more stable. A significant departure of a genotype's regression coefficient from zero will be indicated by a large stability variance. The existence of genetic variation in responses to environmental changes among genotypes or significant genotype $\times$ environment (GE) interaction is the primary basis for stability analysis. Considerable variation among Iranian Damask rose populations has been reported for many traits such as morphological, oil content and flower yield. ${ }^{3,17,18}$ Results of some researches ${ }^{19,20}$ showed environmental effects on the quality and quantity of flower and essence yield. Nirmal \& Sushil Kumar ${ }^{21}$ also introduced Ranisahiba landrace of Damask rose with relative higher essential oil and stable for some morph-physiological traits. Despite the existence of relatively high essential oil landraces of Damask rose, stability and adaptability are important. This study was carried out 
with objective of evaluation of essential oil performance and stability of 35 landraces of Damask rose across various environments.

\section{Materials and methods}

Material and field experiment. Thirty-five landraces of Damask rose from 13 different origin sites of Iran (Figure1 \& Table 1) evaluated for essential oil and stability at seven locations (Sanandaj, Arak, Kashan,
Dezful, Stahban, Kerman and Mashhad) and two years (2007-8) in Iran (Figure1 \& Table 2). The safe and uniform annual saplings of the landraces were planted at each location in March 2004 using randomized complete block design with three replications. Plant spacing was $3^{\mathrm{m}} \times 3^{\mathrm{m}}$ (1111 plants per hectare) and each plot comprised of three plants. Normal cultural practices followed as and when necessary in each location.

Table I Origins of Damask rose landraces according to geographical similarities ${ }^{3}$

*T, temperate; $C$, cool; $W$, war; $A$, arid; $S A$, semi arid; $H$, humid

Yearly mean temperature in warm, temperate and cool climates are $15-25^{\circ} \mathrm{C}, 10-15^{\circ} \mathrm{C}$ and $0-5^{\circ} \mathrm{C}$, respectively.Yearly mean rainfalls in semi-humid, semi-arid and arid climates 600-1400mm, 300-600 and 100-300mm, respectively

\begin{tabular}{llllllll}
\hline Landraces & Origin site & Province(s) included & Climate* & Landraces & Origin site & Province(s)included & Climate* \\
\hline ISI to ISI0 & OsI & Isfahan & T,A & ZAI, QZI & Os8 & Zanjan, Qazvin & CT,SA \\
EAI,WAI, ARI & Os2 & East and west Azerbaijan,Ardabil & CT, SA & SMI, SM2, QMI & Os9 & Semnan, Qom & WT,A \\
ILI, KSI & Os3 & Kermanshah, Illam & T,SA & FA2, KMI & OsI0 & Fars, Kerman & T,SA,A \\
THI,AKI & Os4 & Tehran, Markazi & CT,SA & KRI, HAI & OsII & Kurdistan, Hamedan & C,SA \\
CMI, LOI & Os5 & Chaharmahall, Lorestan & CT,T,SA & GUI & OsI2 & Guilan & T,H \\
KO2 & Os6 & Razavi Khorasan & T,SA & YZI,YZ2 & OsI3 & Yazd & WT,A \\
KZI, HOI, BAI & Os7 & Khuzestan, Hormozgan, Sistan & W,A & & & & \\
\hline
\end{tabular}

Table 2 Some ecological parameters and essential oil content (EO) data of the research locations

$* *$ and * denote significant at $p \leq 0.01$ and $p \leq 0.05$ respectively.

EOMean, essential oil content (EO) mean of location ( ppm); r, correlation coefficient of EO in 2007 with 2008; Vg, Genetic variance component of EO among locations; $V r$ residual variance of $E O ; c$ int, confidence interval for the location mean of essential oil content

\begin{tabular}{|c|c|c|c|c|c|c|c|c|c|c|c|c|c|c|}
\hline \multirow[b]{2}{*}{ Locations } & \multicolumn{8}{|c|}{ Ecological parameters } & \multicolumn{6}{|c|}{ Resulted datas } \\
\hline & $\begin{array}{l}\text { Altitude } \\
\text { (m) }\end{array}$ & $\begin{array}{l}\text { Average } \\
\left({ }^{\circ} \mathrm{C}\right) \\
\text { TOpt }\end{array}$ & $\begin{array}{l}\text { temp } \\
\text { TMax }\end{array}$ & rature & $\begin{array}{l}\text { Relative } \\
\text { humidity } \\
(\%)\end{array}$ & $\begin{array}{l}\text { Annual } \\
\text { rainfall } \\
(\mathrm{mm})\end{array}$ & $\begin{array}{l}\text { A n n u a I } \\
\text { evaporation } \\
(\mathrm{mm})\end{array}$ & $\begin{array}{l}\text { Total } \\
\text { sunny } \\
\text { hours }\end{array}$ & $\begin{array}{l}\text { EO } \\
\text { Mean } \\
(p p m)\end{array}$ & $\mathbf{r}$ & $\mathbf{V g}$ & $\mathbf{V r}$ & Df & C \\
\hline Sanandaj(LI) & 1373.4 & 16 & 21.4 & 5.4 & 47 & 462.4 & 1340 & 2860 & 1041 & $0.4 I^{* *}$ & |254.| & 1870.8 & 34 & $\begin{array}{l}104.1 \pm \\
14.8\end{array}$ \\
\hline Arak ( L2) & 1708 & 13.8 & 20.7 & 6.9 & 46 & 341.5 & 1750 & 2973.3 & 36.7 & 0.25 & 91.2 & 359.9 & 29 & $\begin{array}{ll}36.7 \quad \pm \\
7.1\end{array}$ \\
\hline Kashan (L3) & 982.3 & 14 & 26.1 & 12.1 & 40 & 138.8 & 2526 & 2906.2 & 680.6 & $0.83 * *$ & 21169.5 & 4557 & 34 & $\begin{array}{l}680.6 \pm \\
23.2\end{array}$ \\
\hline Dezful (L4) & 82.9 & 16.2 & 32 & 15.8 & 48 & 343.8 & 2334 & 3066.1 & 217.6 & $0.34^{*}$ & 5781.3 & 12307 & 28 & $\begin{array}{l}217.6 \pm \\
41.9\end{array}$ \\
\hline Stahban (L5) & 1288.3 & 16.8 & 27.7 & 10.9 & 39 & 293.1 & 2196 & 3370.4 & 354 & 0.23 & 19692.7 & 10171.2 & 32 & $\begin{array}{l}354 \\
35.6\end{array} \quad \pm$ \\
\hline Kerman (L6) & 1753.8 & 17.8 & 24.7 & 6.9 & 32 & 154.1 & 1800 & 3165.3 & 191.3 & $0.94 * *$ & |7905.| & 1862.4 & 34 & $\begin{array}{l}191.3 \pm \\
14.8\end{array}$ \\
\hline $\begin{array}{l}\text { M a sh h a d } \\
\text { (L7) }\end{array}$ & 999.2 & 14.1 & 21.1 & 7 & 55 & 255 & 1720 & 2887.6 & 393 & $0.42^{* *}$ & |434|.| & 73465 & 33 & $\begin{array}{l}393.0 \pm \\
94.4\end{array}$ \\
\hline
\end{tabular}

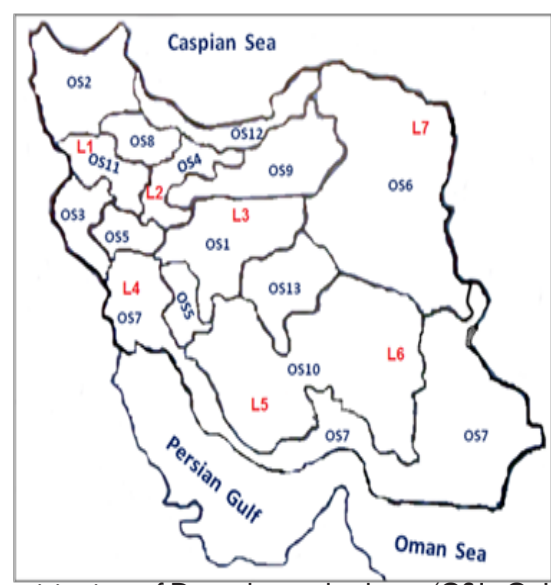

Figure I The origin sites of Damask rose landraces(OSI-Os I3) and research locations (LI-L7) on the map of Iran.
Essential oil extraction process: The essential oils were extracted from $500 \mathrm{~g}$ samples of fresh petals of each replication and landrace in each trial by hydro distillation for $1.5 \mathrm{~h}$ using diethyl ether as solvent. The oils were dried over anhydrous sodium sulfate. The essential oil ratio (EO) of each sample was calculated as the essential oil weight relative to the fresh petal weight.

Statistical analysis: Initial ANOVA for essential oil of 35 Damask rose landraces (a perennial plant) in 7 locations and 2 years was performed based on the complete randomized block design with 3 replications as split-split plot in times (Location as main factor, landrace as sub factor and year as sub-sub factor) as following model: 


$$
X_{\mathrm{iij} k}=\mu=L_{j}+R(L)_{i(\mathrm{j})}+G_{i}+L G_{i j}+R G(\mathrm{~L})_{\mathrm{i} i(j)}+Y_{k(j)}+G Y(\mathrm{~L})_{i k(\mathrm{j})}+R Y(\mathrm{~L})_{\mathrm{i} k(\mathrm{j})}+{ }^{a}{ }_{\mathrm{i} i k(\mathrm{j})}
$$

Where $X_{i j i k}$ is essential oil of $i$ th replication of $i$ th genotype at $j$ th location and $k$ th year, $\mu$ is population mean, $L$ is effect of location, $G$ is effect of genotype (landrace), $Y$ is effect of year within location and $E$ is residual effects or error. After, determining of significance of landrace $\times$ location (GL) and landracexyear (location) (GY/L) interactions, stability parameters were estimated. The softwares of Minitab-14 and IRRISAT were used for statistical analyses.

Stability parameters estimation: The stability model proposed by Eberhart \& Russell ${ }^{1}$ and Shukla's ${ }^{2}$ stability variance $\left(\sigma_{i}^{2}\right)$ was used to estimate stability parameters as follows.

Regression of essential oil on environmental index (bi): As described by Finlay \& Wilkinson, ${ }^{22}$ Singh \& Chaudhary: ${ }^{23}$

$$
\mathrm{bi}=\left(\sum \mathrm{Y}_{\mathrm{ij}} \mathrm{I}_{\mathrm{j}}\right) / \sum \mathrm{I}_{\mathrm{j}}
$$

Where $Y_{i j}$ is yield of the $i$ th landrace in the $j$ th environment and $I_{j}$ is environmental index and $I_{j}=\bar{Y}_{o j}-\bar{Y}_{o o}$ where $\bar{Y} 1_{o j}$ is essential oil mean of the $j$ th environment and $\bar{Y}_{o o}$ is the total mean. The regression coefficients $\left(\mathrm{b}_{\mathrm{i}}\right)$ were tested via $\mathrm{t}$ - test as $\mathrm{t}=(\mathrm{b}-\beta) / \mathrm{S}_{\mathrm{b}}$ where $\mathrm{S}_{\mathrm{b}}=\sqrt{ }\left(\mathrm{Mse}_{\mathrm{a}} / \sum \mathrm{I}_{\mathrm{j}}{ }^{2}\right)$, Mse is pooled error and $\beta=$ expected value of one.

Variance due to deviation from regression $\left(\mathbf{S d}_{\mathrm{i}}{ }^{2}\right)$ : As described by

Eberhart \& Russell, ${ }^{1}$ Singh \& Chaudhary: ${ }^{23} \operatorname{Sd}_{\mathrm{i}}{ }^{2}=\left(\sum \ddot{\mathrm{a}}_{\mathrm{ij}}{ }^{2}\right) / \mathrm{q}-2$ where

$$
\sum \delta_{\mathrm{ij}}^{2}=\left(\sum_{\mathrm{j}} \mathrm{Y}_{\mathrm{ij}}^{2}-\mathrm{Y}_{\mathrm{io}}^{2} / \mathrm{q}\right)-\left(\sum_{\mathrm{j}} \mathrm{Y}_{\mathrm{ij}} \mathrm{I}_{\mathrm{j}}\right)^{2} / \sum_{\mathrm{j}} \mathrm{I}_{\mathrm{j}}{ }^{2}
$$

Where $q$ is the number of environments, $\Sigma \delta_{i j}{ }^{2}$ is sum of squares (SS) of deviations, $\bar{Y}_{i o}$ is mean yield of genotype $i$ across environments, $\left(\sum_{\mathrm{j}} \mathrm{Y}_{\mathrm{ij}}{ }^{2}-\mathrm{Y}_{\mathrm{io}}{ }^{2} / \mathrm{q}\right)$ is total sum of squares (SS) and $\left(\sum_{\mathrm{j}} \mathrm{Y}_{\mathrm{ij}} \mathrm{I}_{\mathrm{j}}\right)^{2} / \Sigma_{\mathrm{j}} \mathrm{I}_{\mathrm{j}}^{2}$ is $\mathrm{SS}$ of regression. $\mathrm{Sd}_{\mathrm{i}}^{2}$ of genotypes were tested with pooled error (MSe).

Shukla's (1972) stability variance $\left(\sigma_{i}^{2}\right)$ : is estimated as:

$$
\dot{o}_{i}^{2}=p /[(p-2)(q-1)] W_{i}-S S(G E) /[(p-1)(p-2)(q-1)]
$$

where $W_{i}=\Sigma_{j}\left(Y_{i j}-\bar{Y}_{i o}-\bar{Y}_{o j}+\bar{Y}_{o o}\right)^{2}$ and $\Sigma_{\mathrm{i}} \mathrm{W}_{\mathrm{i}}=\mathrm{SS}(\mathrm{GE})$

There $p$ is the number of genotypes, SS (GE) is the genotype $\times$ environment interaction sum of squares.

Tate 3 Combined analysis of varince for essential oil content of 35 Danask

Table 3 Combined analysis of variance for essential oil content of 35 Damask rose landraces in 7 locations and 2 years in Iran(The original data have been multiplied in 1000)

** and ${ }^{n s}$ denote significant at $p \leq 0.01$ and non significant respectively.

\begin{tabular}{lllll}
\hline Sources of Variation(SV) & DF & SS & MS & Explained(\%) \\
\hline Location & 6 & 66.58 & $11.11^{* *}$ & 35.8 \\
Rep (Location) & 14 & 2.22 & 0.16 & 1.2 \\
Landrace & 34 & 6.98 & $0.21^{* *}$ & 3.7 \\
Landrace $\times$ Location & 204 & 51.17 & $0.25^{* *}$ & 27.5 \\
Rep $\times$ Landrace (Location) & 476 & 5.69 & 0.01 & 3.1
\end{tabular}




$\begin{array}{lllll}\text { Table Continued..... } & & & & \\ \text { Year (Location) } & 7 & 10.15 & 1.45^{* *} & 5.5 \\ \text { Landrace } \times \text { Year (Location) } & 238 & 32.66 & 0.14^{* *} & 17.6 \\ \text { Rep. × Year (Location) } & 14 & 2.53 & 0.18^{* *} & 1.4 \\ \text { Error } & 397 & 7.98 & 0.02 & \\ \text { Total } & 1390 & 185.96 & & \\ \text { Location (Linear) } & 1 & 11.3 & 11.30 * * & 46.4 \\ \text { Landrace } \times \text { Location (Linear) } & 34 & 2 & 0.058 \mathrm{~ns} & 8.2 \\ \text { Pooled deviation from regression }\left(\sum \text { Sdi2 }\right) & 175 & 9.5 & 0.054 * * & 39 \\ \text { Pooled error } & 465 & 1.55 & 0.003 & \end{array}$

Finally, five landraces of CM1, QM1, KZ1, KS1 and HO1 with 277, 281, 238, 233 and 245 ppm respectively EO were stable GL interaction based on the Eberhart \& Russell ${ }^{1}$ model. All of these stable landraces for GL interaction, located among the first ten stable landraces for EO according Shukla ${ }^{2}$ model with the least stability variance $\left(\sigma_{i}^{2}\right)$. The correlation of stability variance $\left(\sigma_{i}^{2}\right)$ of genotypes between 2007 and 2008 (reproducibility of the stability variance) was $\mathrm{r}=0.15$ and those that in locations were $\mathrm{r}=0.81^{* *}$ and $\mathrm{r}=0.54^{* *}$ respectively.

\section{Discussion}

The large environmental sum of squares (Nearly half of total sum of squares) indicated that environments were diverse and large differences among environmental means causing most of the variation in essential oil. Because of varying ecological conditions of studied locations in this research (seven areas involving almost all parts of Iran) (Figure 1), observed differences among locations and environments were expected. According to Table 2 and the obtained results, with the exception of two locations of Arak (L2) and Stahban (L5) the reproducibility between the years, measured by the correlation (Table 2 ), was generally acceptable. There were wide ecological variations both between and within two groups of high essential oil locations [Kashan (L3), Mashhad (L7) and Stahban (L5) with 476 ppm and low essential oil ones [Dezful (L4), Kerman (L6), Sanandaj (L1) and Arak (L2)] with $137 \mathrm{ppm}$ mean of essential oil. The results suggest significant variation among landraces for essential oil. The existence of genetic variation is the primary base for breeding programs; therefore, selection for this trait could be possible. In accordance to this results, Tabaei Aghdaei et al. ${ }^{3,17}$ and Babaei et al., ${ }^{18}$ also found significant mean square among landraces for essential oil. Generally, because of asexual reproduction (through cuttings), there is a low genetic variation among Damask rose accessions and landraces, also, in Iran, unlike other countries such as Bulgaria and Turkey the main goal of rose cultivation isn't essential oil, but is flower and rose water production. Thus, the Damask rose landraces haven't been subjected to genetic improvement for essential oil and there isn't a considerable genetic diversity among Iranian landraces. This can be a description for low portion of genetic (landrace) variance in total variation for essential oil in present study (about 4\%). Although there were varying origin sites, climates and ecological conditions in both high and low essential oil landraces groups, in addition, most of Damask rose landraces belonged to temperate, warm temperate and arid regions such as SM2 and SM1 (OS9), AK1 (OS4), some of Isfahan group of landraces such as IS9 and IS10 (OS1) and BA1 (OS7) produced higher essential oil than those originated from cool, cool temperate, semi-arid and humid regions such as GU1(OS12), HA1(OS11), KO2 (OS6) and AR1(OS2). Among the first ten superior landraces for essential oil, two of them were from origin site 1 (Isfahan) that wholly originated from Kashan area. Kashan is the main source of Damask rose landraces and Kashan farmers have longed experience in cultivation and production of Damask rose and rose water in Iran. Although the main objective of Kashan farmers is flower and rose water production, this result suggests of the effective role of selection (has been accomplished by traditional farmers either arbitrarily or randomized) for flower yield and essential oil improvement. The results showed high genetic (landrace) variance for essential oil between 2 years among studied locations (from 91.2 in Arak to 21169.5 in Kashan). In accordance to this, the non overlapping confidence intervals (Table 2) indicate highly significant differences in essential oil among the locations and could be important in practical implications. The significant landrace $\times$ location (GL) interaction indicating that essential oil is highly influenced by the changes in environments, thus leading to extension of analysis for estimating stability parameters. The magnitude of GE sum of squares was 12 times larger than of the genotypes $(\mathrm{G})$, indicating that there were differences in genotypic response to environments. This variability was mainly due to the ecological characteristics across experimental locations and years. Based on the results, both landrace $\times$ environment (GE) and landrace $\times$ location (GL) interactions were mainly crossover or qualitative interaction that according to Gregorius \& Namkoong ${ }^{24}$ and Baker ${ }^{16}$ can be used in breeding practices. An interesting result of this study was the high relative consistency of type and order of the stable genotypes with two studied stability method of Eberhart \& Russell ${ }^{1}$ and Shukla ${ }^{2}$ both in years (2007-8) individually and locations for GL interaction. This could be due to the fact that both of Eberhart \& Russell ${ }^{1}$ and Shukla ${ }^{2}$ model measure dynamic stability of genotypes in environments, thus the high compliance of stable (adaptable) genotypes in them can be natural and expectable. As conclusion, according to Eberhart \& Russell ${ }^{1}$ considerations ( $b$ equal to unity, $S_{d}^{2}$ and equal to zero) and Shukla ${ }^{2}\left(\sigma^{2}\right.$ or stability variance equal to zero), the landraces of CM1, QM1, KZ1, KS1 and HO1 were stable in locations. Kempton \& Fox $^{25}$ described adaptation as yield stability in spatial dimension so we can announce the stable landraces in locations as adaptable and compatible ones. According to Ramagosa \& Fox $^{26}$ adaptability or stability of a genotype often relates to physiological, morphological and phonological mechanisms and accumulation of tolerance to a number of stresses is the key to wide adaptation. The stable Damask rose landraces by Eberhart \& Russell ${ }^{1}$ method produced essential oil about average of landraces and also, absence of high essential oil landraces such as SM2, IS4, SM1, AK1 and BA1 among stable and adaptable ones, suggesting that this method measure general stability and adaptability.

\section{Conclusions and recommendations}

The results of this study suggest that a large portion of essential oil variation was attributed to environment (Location-year) and 
landrace $\times$ environment (GE) effects. There were high variations in both essential oil and response to environmental changes among Damask rose landraces of Iran, which can be used in breeding programs. Both essential oil and stability of essential oil are influenced by genetic and environmental factors. Most of Damask rose landraces belonged to temperate, warm temperate and arid regions produced higher essential oil than those originated from cool, cool temperate, semiarid and humid regions. The significant non-linear component of the landrace $\times$ location (GL) interaction was an indication of the importance of unpredictable genotype response to environmental changes and instability of performances of some landraces over locations. As conclusion, according to Eberhart \& Russell ${ }^{1}$ considerations ( $b$ equal to unity and $S_{d}^{2}$ equal to zero) and Shukla's ${ }^{2}\left(\sigma^{2}\right.$ or stability variance equal to zero), the landraces of CM1, QM1, KZ1, KS1 and HO1 were stable in locations. Both models of Eberhart \& Russell ${ }^{1}$ and Shukla' ${ }^{2}$ showed almost same results in determination of genotypes with dynamic stability in locations. The stable and adaptable Damask rose landraces by Eberhart \& Russell ${ }^{1}$ method produced essential oil about average of landraces. Absence of high essential oil landraces among stable ones, suggesting that selecting for essential oil stability and adaptability over environments and locations could result in lower oil. Finally, taking into consideration of essential oil, stability and adaptability potential, we recommend the landraces of CM1 as moderate essential oil landrace with general stability and adaptability in different environments and locations. According to Singh \& Gupta ${ }^{27}$ variety stability has genetic control thus the landrace of CM1 can be used as a parent-in-crosses to transfer genetic stability for essential oil to progenies. Finlay \& Wilkinson ${ }^{22}$ pointed out that genotypes that have a slope (b value) greater than unity are specifically adapted to high yielding environments, so the landraces of SM1 and BA1 can be recommended as superior essential oil with specific adaptability for warm and arid southern part of Iran such as Khuzestan, Kerman, Sistan etc. and the landraces of SM2 and AK1 for temperate and cool areas such as the northern half (Isfahan, Markazi, Khorasan etc.) in Iran.

\section{Acknowledgements}

This research was supported by Research Institute of Forest and Rangelands (RIFR) of Iran. The authors are grateful to the co-executors and field staff of Agricultural and Natural Resources Research Centers of Kurdistan, Hamedan, Markazi, Isfahan, Khuzestan, Fars, Kerman and Khorasan for their assistance in data collection and maintaining the field trials

\section{Conflict of interest}

Authors declare that there is no conflict of interest.

\section{References}

1. Eberhart SA, Russell WA. Stability parameters for comparing varieties Crop Sci. 1966;6:36-40.

2. Shukla GK. Some statistical aspect of genotype-environment components of variability. Heredity. 1972;29:237-245.

3. Tabaei Aghdaei SR, Babaei A, Khosh Khui M, et al. Morphological and oil content variations amongst Damask rose (Rosa damascena Mill.) landraces from different regions of Iran. Scientia Horticulturae. 2007;113(1):44-48.

4. Mahmood NS, Piacente C, Pizza A, et al. The anti HIV activity and mechanisms of action of pure compounds isolated from Rosa damascena. Biochem Biophys Res Commun. 1996;229(1):73-79.

5. Ozkan G, Sagdic O, Baydar NG, et al. Antioxidant and anti bacterial activities of Rosa damascena flower extracts. Food Sci Technol Int 2004;10:277-281.
6. Morales AC, Paragas AA, Carangal VR. Phenotypic stability for grain yield in mungbean (Vigna radiate (L), Wilczek). FLCG Newslett. 1991;16:12-15.

7. Vogler WD, Perets S, Stephenson AG. Floral plasticity in an iteroparous plant: the interactive effects of genotype, environment and ontogeny in Campanula rapunculoides. Am J Bot. 1999;86(4):482-494.

8. Paulo SG, Fujihara AF, Ortolant AA, et al. Phenotypic stability and genetic gains in six-year girth growth of Hevea clones. Pesquisa Agropecuária Brasileira. 1999;34(7):1223-1232.

9. Omokhafe KO. Interaction between flowering pattern and latex yield in Hevea brasiliensis Muell. Arg. Crop Breed Appl Biotechnol. 2004;4:280 284.

10. Wachira F, Ngetich W, Omolo J, et al. Genotype - environment interactions for tea yields. Euphytica. 2002;127(2):78-89.

11. Freeman GH. Statistical methods for the analysis of genotype-environment interactions. Heredity. 1973;31(3): 339-354.

12. Bernardo R. Quantitative traits in plants. Stemma Press. 2002. 369 p.

13. Falkenhagen ER. A comparison of the AMMI method with some classical statistical methods in provenance research: A case of the South African Pinus radiata trials. Forest Genetics. 1996;3(2): 81-87.

14. Kanzler A. Genotype $\times$ Environment Interaction in Pinus patula and its Implications in South Africa. USA: Department of Forestry, North Carolina State University. 2002. 249 p.

15. Wricke G. On a method of understanding the biological diversity in field research. Z Pflanzenzuchtg. 1962;47:92-96.

16. Baker RJ. Tests for crossover genotype - environment interactions. Can J Plant Sci. 1988;68(2):405-410.

17. Tabaei Aghdaei SR, Rezaei MB, Jebeli M. Flower yield and morphological characteristics in some genotypes of Rosa damascena. Iran J Med Arom Plant. 2004;20(1):111-122.

18. Babaei A, Tabaei Aghdaei SR, Khosh khui M, et al. Microsatellite analysis of Damask rose (Rosa damascena Mill.) accessions from various regions in Iran reveals multiple genotypes. BMC Plant Biol. 2007;7:12-19.

19. Misra A, Sharma S, Singh A, et al. Influence of topographical and edaphic factors on Rose II. Flowering quality and quantity. Commun Soil Sci Plant Anal. 2002;33:15-18.

20. Baydar H, Baydar NG. The effects of harvest date, fermentation duration and Tween 20 treatment on essential oil content and composition of industrial oil rose (Rosa damascena Mill.). Industrial crops and products. 2004;21(2): 251-255.

21. Nirmal K, Sushil Kumar P. High yielding stable plant of Rosa damascena, called "Ranisahiba". India: Council of Scientific and Industrial Research; 2002.

22. Finlay KW, Wilkinson GN. The analysis of adaptation in plant breeding programs. Aust J Agri Res. 1963;14(6):742-754.

23. Singh RK, Chaudhary BD. Biometrical methods in quantitative genetic analysis. India: Kalyani Publishers; 1977. 288 p.

24. Gregorius HR, Namkoong G. Joint analysis of genotypic and environmental effects. Oetical Applied Genetics. 1986;72(3):413-422.

25. Kempton RA, Fox PN. Statistical Methods for Plant Variety Evaluation. London: Chapman \& Hall; 1997;139-161.

26. Ramagosa I, Fox PN. Genotype $\times$ environment interaction and adaptation. In: Hayward MD, Bosemark NO, Romagosa I. Editors. Plant breeding. principles and prospects. London: Chapman \& Hall; 1993;373-390.

27. Singh SV, Gupta PK. Phenotypic stability for tuber yield in Potato (Solanum tuberosum L.). Ind J Gen Plant Breed. 1988;48:9-12. 